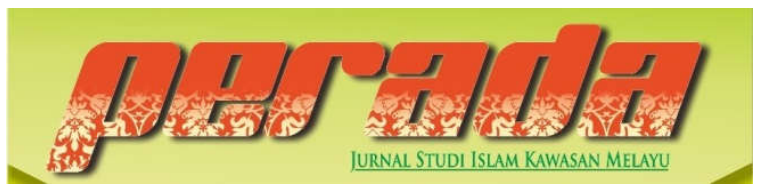

\author{
Perada: Jurnal Studi Islam Kawasan Melayu \\ ISSN 2656-7202 (P) ISSN 2655-6626 (O) \\ Volume 4 Nomor 1, Januari-Juni 2021 \\ DOI: https://doi.org/10.35961/perada.v4i1.280
}

\title{
REKONTRUKSI MAKNA JIHAD DAN KONTEKSTUALISASINYA DI ERA MODERN
}

\author{
Irhamudin \\ UNU Surakarta \\ irhamudinirhamudin79@gmail.com
}

\begin{abstract}
Merupakan suatu kesalahan fatal ketika Terorisme disamakan dengan ajaran jihad dalam agama Islam. Terorisme yang dalam bahasa Arab diistilahkan dengan kata alirhâb tidak diajarkan dalam al-qur'an. Meskipun dalam Surat al-Anfal: 60 tertulis kata "turhibûna", namun ini tidak bisa dijadikan dalil bahwa terorisme merupakan ajaran Islam. Kata "turhibûna" di sini lebih kepada menakuti musuh di medan perang. Maka, dengan menelaah buku-buku turats dan kontemporer, makalah sederhana ini mencoba untuk menelusuri beberapa kesalahpahaman terhadap jihad. Kesalahan tersebut kemudian dikoreksi dengan merujuk kepada pendapat asli dari para ulama, yang dalam makalah ini mengambil pendapat Ibn Qayyim al-Jauzi. Hasil dari penelusuran menunjukkan bahwa kesalahpahaman terletak pada makna dan konsep jihad. Sebagaimana yang dipahami oleh sebagian orang bahwa jihad adalah perang di jalan Allah (fi sabîlillah) saja. Padahal, ranah jihad sangat luas. Ibn Qayyim menguraikan bahwa jihad terdiri dari 13 tingkatan. Tingkatan ini bisa dipadatkan menjadi empat pembagian yang salah satunya adalah jihad memerangi kaum kafir. Jihad melawan kaum kafir sendiri tidak diawali dengan menggunakan senjata. Ada tahapan yal ng harus dilalui, sehingga jihad perang baru boleh dilakukan terhadap orang kafir. Dari pembagian ini pula terlihat bahwa jihad perang bukanlah satu-satunya solusi yang digunakan oleh Islam dalam menegakkan kalimatullah. Maka, artikel ini diharapkan mampu menggambarkan jihad dalam Agama Islam yang sesuai dengan alQur'an dan tuntunan Rasulullah SAW.
\end{abstract}

It was a fatal mistake when terrorism equated with the doctrine of jihad in Islam. Terrorism in Arabic word termed as al-Irhab is not taught in the Qur'an. Even in Surah al-Anfal: 60 wrote the word "turhibûna", but it can't be used as the argument that terrorism is taught Islam. The word "turhibûna" here is more to frighten the enemy on the battlefield. By studying the turats and contemporary books, this simple paper tries to explore some of the misunderstandings about jihad. Then, those errors will be corrected by refering to the original opinion of the Muslim scholars, which in this paper refered to Ibn Qayyim al-Jawzi's opinions. The results of the study showed that this misunderstanding lied on the meaning and concept of jihad. As understood by 
some people that jihad is a war in the path of Allah (fi sabilillah) only. In fact, the realm of jihad is very wide. Ibn Qayyim explained that jihad consists of 13 levels. These levels can be reduced to four parts, which one of them is fighting the infidels. Jihad against the infidels is not using the weapons. There are several steps that must be passed, so that jihad to infidels can be done. Of this division is also seen that the jihad war is not the only solution used by Islam in upholding Allah's name (kalimatullah). So, this paper is expected to be able to describe the jihad in Islam based on the Qur'an and Prophetic traditions.

Kata Kunci: Jibad, al-Qur'an, al-Sunnah, Ibn Qayyim, Etika.

\section{PENDAHULUAN}

Dewasa ini jihad seringkali dipahami tidak sebagaimana mestinya. Kondisi ini dipicu oleh beberapa sebab, salah satunya interpretasi yang salah terhadap makna jihad, baik yang dipahami oleh beberapa Kaum Muslim atau nonMuslim. Bagi non-Muslim, mereka menilai jihad dalam Islam merupakan situasi yang tidak terkendali, irasional, dan konotasinya perang total. ${ }^{1}$ Fakta ini bisa kita dapatkan dalam sejumlah buku yang ditulis oleh beberapa non-Muslim yang anti terhadap Agama Islam. Jack NelsonPallmeyer dalam Is Religion Killing Us? Menulis:

"The problem of Islam and violence is not limited to incompatible texts but is rooted in the overwhelming preponderance of passages in the Qur'an that legitimate violence, warfare, and intolerance. Violence in service to Allah is both justified and mandated by Allah or Muhammad under the sanction of divine threat. ${ }^{, 2}$

Anehnya, ada Kaum Muslim yang terpengaruh pandangan non-Muslim

1 David Cook, Understanding Jihad, (Los Angeles: University of California Press, 2005), h 1

2 Arti bebasnya, "Permasalahan Islam dan kekerasan tidak terbatas pada teks-teks yang tidak kompatibel (sesuai) saja tetapi berakar dengan jumlah yang banyak dalam ayatayat dalam $\mathrm{Al}$ Qur'an yang melegitimasi kekerasan, peperangan, dan intoleransi (tidak toleran). Kekerasan dalam rangka mengabdikan diri kepada Allah adalah sesuatu yang dibenarkan dan diperintahkan oleh Allah atau Muhammad di bawah sanksi ancaman ilahi." Jack Nelson Pallmeyer, Is Religion Killing Us?, (New York: Continuum, 2003),h. 84 seperti di atas. $^{3}$ Atau ada juga yang berjihad tetapi tidak sesuai dengan etika jihad yang diajarkan oleh Rasulullah SAW dan para sahabatnya. Pada akhirnya konsep jihad yang komprehensif sebagaimana yang diletakkan oleh para ulama pun menjadi salah di mata mereka. ${ }^{4}$ Akibatnya, Islam dituduh sebagai agama yang ditegakkan dan dikembangkan dengan kekerasan. Berangkat dari itu, makalah ini mencoba membahas tentang pengertian jihad, pembagian jihad, dan etika jihad dalam agama Islam yang sesuai dengan ajaran Rasulullah SAW. Pembahasan terhadap tiga hal ini diharapkan mampu menggambarkan konsep jihad dalam agama Islam, sehingga nantinya tidak lagi terjadi reduksi yang salah terhadap makna konsep jihad.

\section{TA'RIF JIHAD}

Ketika berbicara tentang jihad maka tidak lepas dari dua term lain yang terkadang dikaitkan dengannya, al-qitâl dan al-harb. Sekilas, tiga kata ini memiliki kesamaan makna, namun jika ditelurusi lebih lanjut, akan terdapat perbedaan antara satu dengan yang lainnya. Secara etimologi, jihad berasal dari kata kerja jâhada-yujâhidu, masdarnya jihâdan wa

3 Seperti yang penulis dapatkan pada sampul belakang buku "Aku Melawan Teroris" karangan Imam Samudra. Lihat: Abdul Aziz alias Imam Samudra alias Qudama, Aku Melawan Teroris, (Solo: Jazeera, Cet. I, 2004), Cover belakang

4 Fauzun Jamal, Intelijen Nabi: Melacak Jaringan Intelijen Militer dan Sipil Pada Masa Rasulullah, (Bandung: Pustaka Oasis, 2009), h. 151. 
mujâhadatan. Dalam Lisan al-'Arab, Ibnu Mandzur menjelaskan bahwa jihad berasal dari kata al-juhd artinya al-tâqah (kekuatan), al-wus'u (usaha) dan almasyaqqah (kesulitan). ${ }^{5}$ Pendapat Ibnu Mandzur ini senada dengan Muhammad.

Murtadha al-Husni al-Zabidi dalam Tâju al-'Arus, ${ }^{6}$ namun sedikit berbeda dengan Muhammad bin Abi Bakar bin 'Abdi al-Qadir alRazi dalam Mukhtar alShahâh yang menyebutkan jihad berasal dari kata al-juhd artinya al-tâqah, atau aljahd artinya almasyaqqah. ${ }^{7}$ Dengan demikian, asal kata jihad adalah al-jahdu dengan mem-fathah-kan huruf jîm atau al-juhdu dengan mendhammah-kan huruf jîm, yang artinya al-tâqah (kekuatan), alwus'u (usaha) dan al-masyaqqah (kesulitan). Selanjutnya, kata al-juhdu bermetamorfosa menjadi jihad. Jihad dalam kamus Mukhtar al-Shahah adalah badzlu al-wus'i (mengerahkan kemampuan). ${ }^{8}$ Sementara dalam kamus Tâju al- 'Arus terdapat dua pengertian tentang jihad: (1) al-qitâlu ma'a al'aduwwi, kal mujâhadah (memerangi musuh seperti bermujahadah) ${ }^{9}$ dan (2) muhârabatu al-a'dâ', wa huwa almubâlaghah wa istifrâghu mâ fî al-wus'i wa al-tâqati min qawlin aw fi'lin. Wa almurâd bi al-niyyah ikhlash al-'amal lillâhi ta'ala (memerangi musuh dengan penuh kesungguhan dan kekuatan, baik berupa perkataan atau perbuatan, dengan niat ikhlas karena Allah SWT). Adapun

5 Ibn Mandzur, Lisân al-'Arab, jilid 1, (Kairo: Darul Ma'arif, 1119), h. 708.

6 Muhammad Murtadha al-Husni alZabidi, Tâju al-'Arus, (Kuwait: Pemerintah Kuwait, 1385H/1965M), h. 534.

7 Muhammad bin Abi Bakar bin 'Abdi alQadir ar-Razi, Mukbtar al-Shabâh, (Beirut: Maktabah Lubnân, 1986), h. 48.

${ }^{8}$ Kemampuan di sini berarti keluasaan dari waktu, usaha yang keras dan mengerahkan tenaga. Ibid., 48

9 Mujahadah di sini maksudnya adalah perang membela agama. Pusat Bahasa Departemen Pendidikan Nasional, Kamus Bahasa Indonesia. (Jakarta: Balai Pustaka, 2008), 976. dalam Lisânu al-'Arab tertulis, jihad adalah qâtala wa jâhada fî sabîlillah (berperang dan berjuang di jalan Allah). ${ }^{10}$ Dari pemaparan tentang ta'rîf jihad di atas, maka dapat disimpulkan bahwa secara etimologi jihad adalah perjuangan dengan mengerahkan segenap kemampuan, baik perjuangan dalam bentuk melawan musuh di medan pertempuran, atau perjuangan tanpa terjun ke medan pertempuran. Sehingga muslim yang berjuang dengan menuntut ilmu kemudian berdakwah di jalan Allah SWT, sudah termasuk mujâhid (pelaku jihad).

Sementara dari sisi terminologi jihad memiliki makna yang beragam. Menurut Lembaga Riset Bahasa Arab Republik ArabMesir dalam al-Mu'jam alWasith, jihad adalah qitâlun man laisa lahu dhimmatun min al-kuffâr (memerangi orang kafir yang tidak ada ikatan perjanjian damai). ${ }^{11}$ Pengertian ini terlihat lebih mengkhususkan kepada makna jihad perang. Dalam kamus Mu'jam alMushthalahât wa al-Fadz alFiqhiyyah, Abdurrahman Abdul Mun'im menulis pengertian jihad menjadi empat: (1) mengerahkan segenap kemampuan dalam memerangi orang kafir, (2) berjuang dari keragu-raguan dan godaan syahwat yang dibawa oleh setan, (3) berjuang dengan keyakinan yang teguh disertai dengan usaha yang sungguhsungguh dengan cara mengajak kepada yang ma'ruf dan meninggalkan kemungkaran terhadap orang-orang fasik, dan (4) dalam makna serupa dengan pengertian yang ketiga, namun lebih khusus lagi yaitu terhadap orang-orang kafir yang memerangi umat Islam. $^{12}$

${ }^{10}$ Ibn Mandzur, Lisân..., I/710.

11 Majma' al-Lughah al-'Arabiyah Jumhuriyah Mishra al-'Arabi, al-Mu’jam al-Wasith, (Kairo: Maktabah as-Syurûq al-Dauliyah, Cetakan IV, 1429H/2008 M), 147.

12 Abdurrahman Abdul Mun'im, Mu'jam alMustalahât wa al-Faz al-Fiqhiyah, (Kairo: Dâru alFadlah, Cetakan I), 543. 
Darinya dapat dipahami bahwa pengertian jihad tidak sekadar berperang di medan pertempuran, namun lebih luas dari itu. Sementara menurut Abdurrahman bin Hamad Ali Imran, jihad terbagi dua, umum dan khusus. Dalam pengertian umum, jihad adalah seorang muslim bersungguh-sungguh dalam menggapai sesuatu yang bisa mendekatkan dirinya kepada Allah SWT, serta menjauhkan diri dari apa saja yang dilarang oleh-Nya. Sedangkan dalam pengertian khusus adalah memerangi kaum kafir dalam rangka menegakkan kalimatullah (syariat Allah SWT). ${ }^{13}$ Definisi yang diberikan Abdurrahman ini menunjukkan bahwa pengertian jihad secara umum adalah segala perbuatan seorang muslim yang dilakukan dengan segenap kemampuan dan kesungguhannya untuk mencapai ridha Allah. Di sini juga dapat dipahami bahwa hanya pengertian secara khususlah yang berkonotasi perang di medan pertempuran yang tentu saja membutuhkan syarat-syarat khusus juga untuk merealisasikannya.

Dari pemaparan di atas terlihat bahwa pengertian jihad dari segi terminologi tidak jauh berbeda antara satu pendapat dengan yang lainnya. Perbedaannya terletak pada luas sempitnya definisi yang diberikan. Dalam arti yang sempit (khusus), jihad berperang melawan orang kafir di medan pertempuran. Sementara dalam arti yang luas (umum) ia berarti kesungguhan seorang muslim dalam beribadah yang niatnya untuk mencapai ridha Allah SWT

\section{JIHAD DALAM AL-QUR'AN}

Selain dari berbagai kamus, makna jihad juga bisa ditelusuri dari beberapa ayat al-Qur'an. Dalam al-Qur'an terdapat 36 ayat yang berkaitan dengan jihad, atau yang di dalamnya mengandung unsur kata

13 Abdurrahman bin Hamad Ali Imran, alJihâdu, (Riyadh: al-Qashim, Cetakan I, 1390 H), 5 jihad.16 Sementara menurut Yusuf alQaradhawi, kata jihad dengan berbagai bentuknya disebut sebanyak 34 kali dalam al-Qur'an. Kata jihad kemudian banyak digunakan dalam arti peperangan (al-qitâl) untuk menolong agama dan kehormatan umat. Namun bukan berarti jihad hanya sebatas peperangan. Kata jihad dalam alQur'an memiliki beberapa makna, di antaranya; jihad hawa nafsu, jihad dakwah dan penjelasan, jihad dan sabar. Jihad yang semacam ini oleh Yusuf alQaradhawi diistilahkan dengan istilah jihad sipil (al-jihâd al-madani). ${ }^{14}$ Berikut penulis sebutkan tiga contoh makna jihad, yang meliputi jihad perang, jihad moral, dan jihad dakwah dalam al-Qur'an.

Jihad Bermakna Perang Pengertian jihad sebagai perang dapat kita lihat pada Surat al-Tahrîm ayat 9 "Hai Nabi, perangilah orang-orang kafir dan orangorang munafik dan bersikap keraslah terhadap mereka. Tempat mereka adalah Jahannam dan itu adalah seburukburuknya tempat kembali." Berdasarkan redaksinya, ayat ini mudah untuk disalahartikan oleh orang-orang yang phobia terhadap ajaran Islam. Hal ini karena pada redaksi ".... Perangilah orang-orang kafir..." jika dipahami sekilas, maka akan menggambarkan bahwa di manapun ada orang kafir dan munafik, mereka harus diperangi. Namun akan lain halnya jika dilihat lebih dalam lagi maksud dari ayat ini. Dalam tafsir alMarâghi disebutkan bahwa kata jihâd di sini mengandung tiga makna, jihad dengan pedang (saif), jihad dengan argumentasi (hujjah), dan berjihad dengan dalil (burhân). ${ }^{15}$ Terkait dengan kata jihâd dalam ayat ini, M. Quraish Shihab dalam Tafsir al-Mishbah mengatakan bahwa

14 Yusuf Qardhawi, Fiqih Jihad: Sebuah Karya Monumental Terlengkap Tentang Jihad Menurut Al-Qur'an dan Sunnah, (Bandung: Mizan, Cetakan I, 2010), h. lxxv.

15 Ahmad Mustafa al-Marâghi, Tafsir alMarâghi, Jilid 10, (Beirut: Dâru al-Fikr, 1426/2006), h. 106. 
orang kafir dan munafik diperangi karena mereka sering mengotori lingkungan dengan ide dan perbuatan-perbuatan mereka. Dalam penjelasan selanjutnya, ia mengatakan perang terhadap orang kafir dan munafik dalam ayat ini adalah dengan hati, lisan, harta, jiwa, dan kemampuan apapun yang dimiliki. Perintah ini ditujukan kepada Nabi Muhammad SAW, dan agar diteladani oleh umatnya. Kemudian Shihab menyitir pendapat alThabathaba'i yang memahami jihâd dalam arti upaya sungguh-sungguh untuk memperbaiki keadaan mereka (kafir), sehingga mereka beriman dengan benar dan tulus, juga untuk menghindarkan gangguan dan ancaman mereka. Hal ini dengan menjelaskan dan menyampaikan kebenaran kepada mereka. Apabila orang kafir menerima dan percaya, maka misi dakwah tersampaikan, dan bila mereka menolak, jika gangguan dan ancaman orang kafir berlanjut, mereka diperangi. Di sini bisa kita lihat betapa hati-hatinya Islam ketika menggunakan istilah perang. Orang kafir tidak langsung diperangi hanya karena kekafiran mereka, namun ada tahapan dakwah. Tahapan dakwah saja tidak cukup, mereka baru diperangi kalau gangguan dan ancaman mereka berlanjut. ${ }^{16}$

\section{JIHAD BERMAKNA MORAL}

Adapun pengertian jihad sebagai jihad moral bisa kita jumpai dalam Surat al-Ankabût ayat 69. "Dan orang-orang yang berjihad untuk (mencari keridhaan) Kami, benar- benar akan Kami tunjukkan kepada mereka jalan-jalan kami. Dan Sesungguhnya Allah benar-benar beserta orang-orang yang berbuat baik." Menurut Yusuf al-Qaradhawi jihad di sini adalah jihad moral yang meliputi jihad terhadap hawa nafsu dan jihad melawan godaan

${ }^{16}$ M. Quraish Shihab, Tafsir Al-Mishbâh, Vol. XIV, (Ciputat: Lentera Hati, Cetakan II, 2009), h. 182-183. setan. Sehingga jihad perang tidak termasuk dalam ayat ini. ${ }^{17}$

\section{JIHAD BERMAKNA DAKWAH}

Jihad dalam makna dakwah terdapat dalam Surat al-Nahl ayat 110. "Dan Sesungguhnya Tuhanmu (pelindung) bagi orang-orang yang berhijrah sesudah menderita cobaan, kemudian mereka berjihad dan sabar; Sesungguhnya Tuhanmu sesudah itu benar-benar Maha Pengampun lagi Maha Penyayang." Terkait dengan ayat ini, Yusuf alQaradhawi berkomentar, bahwa jihad dalam ayat ini adalah jihad dengan dakwah dan tabligh, serta jihad dalam menanggung penderitaan dan kepayahan. Sebagaimana yang dilakukan Umat Muslim di Makkah sebelum berhijrah ke Habasyah. Di Makkah, mereka mengalami penderitaan, penindasan, pengepungan, dan penyiksaan. ${ }^{18}$ Sehingga, dengan segala bentuk kepayahan yang dialami oleh Kaum Muslim, jihad dalam ayat ini juga mengandung makna jihad sabra

Dalam pelaksanaannya, jihad dapat dirumuskan dalam tiga konteks. Pertama, dalam konteks pribadi, jihad adalah berusaha untuk membersihkan pikiran dari pengaruh-pengaruh ajaran selain Allah dengan perjuangan spiritual di dalam diri, melaksanakan perintah Allah dan menjauhi larangan-Nya. Kedua, dalam konteks komunitas, jihad adalah berusaha agar ajaran-ajaran agama Islam dalam masyarakat ataupun keluarga tetap tegak melalui dakwah dan pembersihan diri dari kemusyrikan. Ketiga, dalam konteks kenegaraan, jihad adalah berusaha menjaga negara (suatu wilayah Islam) dari serangan luar ataupun pengkhianatan dari dalam agar ketertiban dan ketenangan rakyat dalam beribadah di wilayah tersebut tetap terjaga, termasuk di dalamnya adalah pelaksanaan amar ma'rûf

\footnotetext{
17 Yusuf Qardhawi, Fiqih Jihad..., 74

${ }^{18}$ Ibid.
} 
nahi munkar. Jihad ini hanya berlaku di wilayah yang menerapkan Islam secara menyeluruh. ${ }^{19}$ Dari tiga konteks pelaksanaan jihad ini menunjukkan bahwa medan jihad mencakup seluruh lini kehidupan seorang muslim. Dari yang terkecil (pribadi), pertengahan (komunitas), dan yang terluas (negara). Jihad dalam konteks terkecil lebih menekankan kepada pembentukan iman, juga pembersihan iman yang dipengaruhi oleh bisikan setan. Sementara dalam konteks pertengahan dan terluas lebih menitikberatkan kepada proteksi terhadap keutuhan tatanan masyarakat.

Adapaun al-qitâl, secara etimologi adalah ism masdar dari kata kerja qâtalayuqâtilu-muqâtalatan. Al-qitâl berasal dari kata al-qatl yang artinya membunuh. Membunuh di sini sama halnya sebagaimana serigala membunuh mangsa-nya. Ibn Mandzur menulis alqitâl adalah almuqâtalah wa al-muhârabah baina isnaini (peperangan yang terjadi di antara dua kelompok).Sementara Lembaga Riset Bahasa Arab Republik Arab-Mesir dalam al-Mu'jam al-Wasith menyatakan, al-qitâl adalah hâraba (berperang). Dua definisi ini menunjukkan bahwa makna al-qitâl adalah perang di medan pertempuran. Sehingga, al-qitâl bisa direkomendasikan sebagai jihad ketika memenuhi konsekuensi yang telah ditetapkan oleh syariat Islam.

Sementara al-harb merupakan kata asli yang kata kerjanya haraba-yahrubuharban. Dari segi etimologi, al-harb memiliki ragam makna. Dalam al-Mu'jam al-Wasith, artinya al-qitâlu baina fiataini (peperangan yang terjadi di antara dua kelompok). ${ }^{20}$ Di sini arti al-harb sama dengan al-qitâl. Akan tetapi ketika dikomparasikan dengan pendapat al-Sirafi yang tercantum dalam Lisânu al-'Arab, al-

19 M. Imam Pamungkas, Akhlak Muslim Modern: Membangun Karakter Generasi Muda, (Bandung: Marja, Cetakan I, 2012), h. 89-90

${ }^{20}$ Ibid. h. 169 harb memiliki arti yang berbeda dengan al-qitâl. Al-Sirafi mengatakan, al-harb adalah naqîdhu al-silmi (antonim dari kata perdamaian), ia termasuk jenis kata mu'annats $^{21}$ aslinya adalah bentuk kata sifat. Kalau dikatakan sebagai antonim dari kata perdamaian, maka al-harb bisa berarti permusuhan. Sedangkan permusuhan tidak terbatas pada perang saja, permusuhan bisa berwujud antagonisme, bentrokan, kebencian, kesumat, konflik, percederaan, percek-cokan, pergesekan, perselisihan, persete-ruan, pertengkaran, dan pertentangan. Pada akhirnya, tawuran siswa pun bisa dikatakan al-harb karena di dalamnya ada permusuhan. Sehingga, dari pendapat al-Sirafi ini terlihat bahwa makna al-qitâl dengan al-harb berbeda.

Dalam perang, biasanya satu kelompok adalah kelompok yang benar dan adil, sedangkan kelompok lain adalah kelompok yang salah dan zalim. Namun adakalanya kedua kelompok ini adalah kelompok yang zalim. Di sini terlihat bahwa, opini al- Qaradhawi mengenai perbedaan arti al-qitâl dengan al-harb sangat argumentatif. Alasannya, terdapat pada beberapa ciri perang yang biasanya melakukan hegemoni, menindas, merampas kekayaan orang lain, dan senjata yang digunakan pun beragam. Berdasarkan alasan ini pula, penulis lebih setuju dengan pendapat al-Qaradhawi yang membedakan definisi al-qitâl dengan al-harb.

\section{PEMBAGIAN JIHAD}

Salah satu pembagian jihad yang akurat adalah sebagaimana yang dikemukakan oleh Ibn Qayyim alJauziyyah. Dalam kitabnya Zâd al-Ma'âd, Ibn Qayyim menulis jihad terdiri dari

${ }^{21}$ Dalam bahasa arab, untuk membedakan jenis kata maka kata dibagi menjadi ism muzakkar dan ism muannats. Ism muzakkar adalah nama kata yang menunjukkan laki-laki. Sementara ism muannats adalah nama kata yang menunjukkan perempuan. 
empat. Pertama, jỉhâd al-nafs (jihad dalam memperbaiki diri). Kedua, jihâd alsyaithân (jihad melawan syaithan). Ketiga, jihâd al-kuffâr wa almunâffiqîn (jihad melawan orang-orang kafir dan orangorang munafik). Keempat, jihâd al-bâbi alzulmi wa al-bida' wa almunkarât (jihad melawan orang-orang zalim, ahli bid'ah, dan para pelaku kemungkaran). ${ }^{22}$ Ibn Qayyim al-Jauziyyah menjabarkan empat pembagian jihad ini ke dalam tiga belas tingkatan jihad (marâtibu al-jỉhad).

\section{KESIMPULAN}

Jihad dalam agama Islam tidak selamanya bermakna perang. Jihad lebih luas dari sekadar perang. Karena setiap kesungguhan yang dilakukan oleh kaum mulim dalam rangka mendekatkan diri kepada Allah SWT sudah termasuk jihad. Adapun jihad yang sering dimaknai dengan perang merupakan solusi terakhir dalam rangka berdakwah menegakkan kalimatullâh. Karena agama Islam membenci peperangan. Fakta lain yang menunjukkan bahwa jihad tidak sebatas perang adalah ranah jihad yang luas. Hal ini bisa dilihat dari pembagian jihad menurut Ibn Qayyim yang terdiri dari tiga belas tingkat. Dalam tingkatan jihad ini, terlihat bahwa jihad perang merupakan salah satu bagian saja dari jihad. Kemudian, kalaupun harus berperang, perang yang dilakukan umat Islam merupakan perang yang paling manusiawi. Ini terlihat dari etika perang yang bisa dijumpai dalam beberapa Hadis Nabi SAW dan ayat al-Qur'an. Dengan etika perang ini, perang yang dilakukan umat Islam tidak ada tendensi untuk memperkaya diri dan negara.]

${ }^{22}$ Ibn Qayyim al-Jauziyyah, Zâd al-Ma'âd, (Beirut: Daaru al-Kutub al-'Arabi, Cetakan I, 1425H/2005M), h. 415-416.

\section{DAFTAR PUSTAKA}

Al-Albani, Muhammad Nshiruddin. T. Th. Ringkasan Shahih Muslim, Jilid II. T. Tmp: Pustaka Azam.

Anita, Vivi Sofia. 2008. Manusia yang Dicintai dan Dibenci Allah: KucinKunci Menjadi Kekasih Allah. Bandung: Mizan Pustaka.

Cook, David. 2005. Understanding Jihad.Los Angeles: University of California Press. Fauzun Jamal, Intelijen Nabi: Melacak Jaringan Intelijen Militer dan Sipil Pada Masa Rasulullah. Bandung: Pustaka Oasis.

http://www.hidayatullah.com/read/1656 1/23/04/2011/pakar-arabbelandasebut-Islam-agama-kekerasan.html. Dikutip pada tanggal 15-maret $\underline{2021}$

Al-Hasani, 'Alamî zâdah Faidhullâhi. 1426H/2006M. al-Mu'jam alMufahras li Kalimâti al-Qur'an al Musamma bi Fathi arRahmân. Damaskus: Dâr Ibn Katsir, Cet. III. Imran, Abdurrahman bin Hamad Ali. 1390 H. al-Jihâdu. Riyadh: alQashim, Cetakan I.

Al-Jauziyyah, Ibn Qayyim. 1425H/2005M. Zâd al-Ma'âd. Beirut: Dâr al-Kutub al-'Arabi, Cetakan I.

Majma' al-Lughah al-'Arabiyah Jumhuriyah Mishra al-'Arabi. $1429 H / 2008$ M. al-Mu’jam alWasith. Kairo: Maktabah asSyurûq al-Dauliyah, Cetakan IV.

Mandzur, Ibn. 1119 H. Lisân al-'Arab, Jilid 1, Kairo: Darul Ma'arif.

al-Marâghi, Ahmad Mustafa. 1426/2006. Tafsir al-Marâghi. Jilid 10. Beirut: Dâru al-Fikr.

Mun'im, Abdurrahman Abdul. T. Th. Mu'jam al-Mustalahât wa al-Faz alFiqhiyah, (Kairo: Dâru al-Fadlah, Cetakan I. 
Pallmeyer, Jack Nelson. 2003. Is Religion

Killing Us?, New York:

Continuum.

Pamungkas, M. Imam. 2012. Akhlak Muslim Modern: Membangun

Karakter Generasi Muda, Bandung: Marja, Cetakan I.

Pusat Bahasa Departemen Pendidikan Nasional. 2008. Kamus Bahasa Indonesia. Jakarta: Balai Pustaka.

Qardhawi, Yusuf. 2010. Fiqih Jihad: Sebuah Karya Monumental Terlengkap Tentang Jihad Menurut Al-Qur'an dan Sunnah, Bandung: Mizan, Cetakan I.

Ar-Razi, Muhammad bin Abi Bakar bin 'Abdi al-Qadir. 1986. Mukhtar alShahâh. Beirut: Maktabah Lubnân.

Said, Mohammad. T. Th. Aceh Sepanjang Abad, Jilid Kedua. Medan: P.T. Harian Waspada.

Samarkand, Abu Lais Nasr bin Muhammad bin Ahmad bin Ibrahim. 1413H/1993M. Tafsir alSamarkand al-Musamma Bahru al'Ulûm. Beirut: Dâr al-Kutub al'Alamiah.

Samudra, Imam. 2009. Aku Melawan Teroris, (Solo: Jazeera, Cet. I, 2004), Cover belakang.

Shihab, M. Quraish. 2009. Tafsir AlMishbâh, Vol. XIV. Ciputat: Lentera Hati, Cetakan II.

al-Zabidi, Muhammad Murtadha alHusni. 1385H/1965M. Tâj al'Arus. Kuwait: Pemerintah Kuwait.

Zakariya, Abi Husain Ahmad bin Fâris Ibn. T. Th. Maqâyîsu alLughah. Beirut: Dâru al-Fikr 